\title{
Research on Fault Diagnosis of Fin Stabilizer System Based on Optimum Searching Strategy*
}

\author{
Lijun Yu, Jin Zhang, Hui Wang \\ Department of Harbin Engineering University of Automation, Harbin, 150001, China \\ yulijun@hrbeu.edu.cn,yimi.ge@163.com
}

\begin{abstract}
As the composition, working principle and failure data recorded in the process of actual operation, in the nonretractable valve controlled anti-rolling fin system are in-depth analyzed. FTA method is used to set up the fault tree model, and the model is analyzed to determine the failure modes and the main reasons of the fin system. In allusion to the shortage of fault tree analysis method that path searching is not clear enough in actual fault search, the optimum search strategy based on the multi-objective decision in fault diagnosis of fin system is put forward, the path of locating failure cause is realized to be simple, steps of fault diagnosis are optimized, so that the efficiency of diagnosis is improved further.

Index Terms - Fin stabilizer, Fault tree analysis, Optimum search strategy, Searching costs.
\end{abstract}

\section{I . Introduction}

Along with the development of the economy, and the progress of maritime career, higher requirements are put forward during the voyage of ship, such as operability, comfort and security ${ }^{[1]}$. Controllable anti-rolling fin system is the main stable installation equipped with ship, it has been regarded as necessities of the ship as ship's seaworthiness guaranteed. But as a result of that fin is integrated organization composed of machine, electricity and hydraulic, and its structure and technology is complex and parts related to each other closely ${ }^{[2]}$. As the system goes to fault, failure types and causes are complex. The users which only operate simply can hardly find out the failure cause, even the technicians may take a long time to find out fault reason. How to optimize the fault search strategy, short the time of fault locating and improve the efficiency of diagnosis is always a topic people studied on.

\section{Fault tree analysis of fin stabilizer}

\section{A. Brief introduction of FTA}

Fault tree analysis (FTA) is a commonly used fault diagnosis method in practical engineering ${ }^{[3]}$. The possible factors (including hardware, software, environment, etc.) which cause system failure are listed clearly by this method, and the factors are in the form of logic diagram. According to the built fault tree, basic faults can be distinguished, the fault reason can be determined and the occurrence rates can be calculated.

\section{B. Principle of hydromantic control part of fin}

In this paper, non-retractable valve controlled fin is analyzed as a simple, and its working principle is: at startup, pressure regulating electromagnetic relief valve is powered, motor starts with no-load, power on the valve is cut off after $2 \mathrm{~s}$, and pressure buildup, at this moment the zero/roll fin valve is off power, hydraulic oil from the variable pump of constant pressure is pulled into reset hydro-cylinder to reset zero, unlocking valve is powered to be unlocked after 2 s delayed, the zero/roll fin valve is powered after $3 \mathrm{~s}$ delayed from unlocked, reset pressure unloading, fin transfer circuit connected, and fin enter working state after 1s. At stop time, disconnect/reduction wave signal off, zero/roll fin valve is off power delayed $1 \mathrm{~s}$, and hydraulic oil is pulled into the reset oil cylinder to reset to zero, at the same time, unlocking valve is off power to be locked, the motor is stopped as locking in place. The schematic diagram of valve controlled hydraulic system is shown as following:

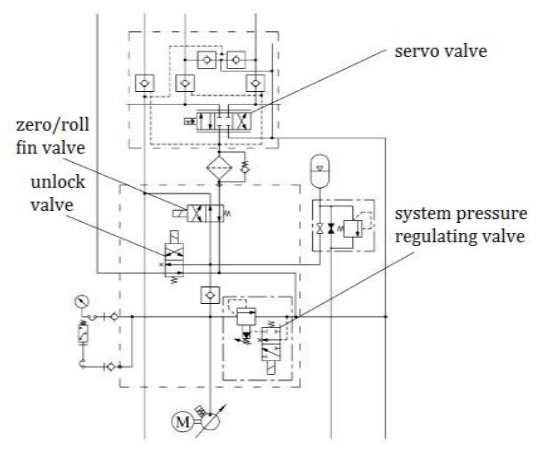

Fig. 1 hydraulic schematic diagram of non-retractable valve controlled fin

\section{Fault tree of fin stabilizer system}

According to the general establishing steps of the fault tree, the fault of fin stabilizer is taken as the top event, and the direct reasons "the system cannot start ", "fin stabilizer can't stabilize" and "halt of the fin "are taken as the second level. The reason "system can't start" has two branches: "power supply" and "power not supply ". Furthermore, system failure under the "power supply" reason is caused by class components fault, such as electric control system, electrohydraulic servo system. Fault of components can be found step by step, such as servo valves, potentiometer, overflow valve, amplifier and so on. Finally, the entire bottom event (possible reason) of the fault tree can be found. The simplified fault tree of the fin stabilizer is shown in figure 2 .

\footnotetext{
This paper is funded by the central university basic research operations special fund project (HEUCF041311), and the International Exchange Program of Harbin Engineering University for Innovation-oriented Talents Cultivation.
} 


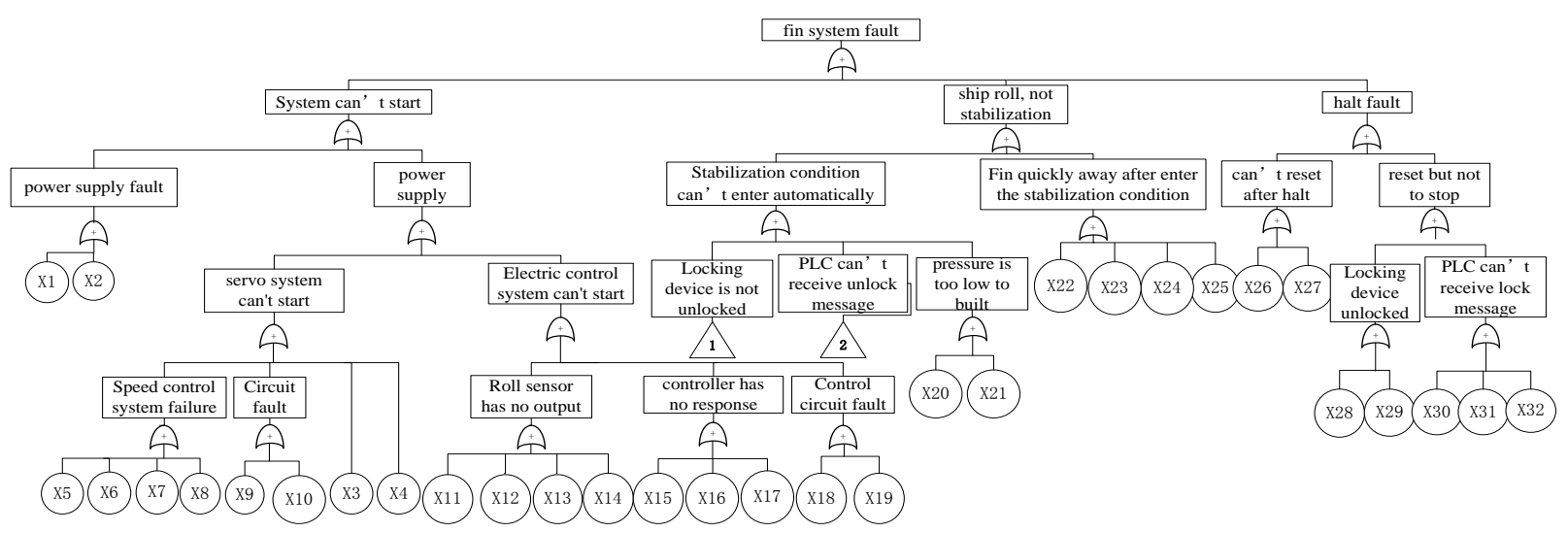

Fig 2 simplified fault tree of the fin stabilizer

\section{Optimum searching strategy}

1) For complex systems, the traversal search according to fault tree analysis always causes low efficiency. So it is necessary to find an optimal search sequence, under the premise of consideration the probability, the search cost and other factors by applying to intelligent diagnosis system, for improving the efficiency of equipment diagnosis ${ }^{[6]}$. Minimum cut sets are set to be $X_{1}, X_{2}, \ldots, X_{n}$, the probability of each bottom event when the system failure occurs are $P_{1}, P_{2}, \ldots, P_{n}$, and the corresponding search cost are $C_{1}, C_{2}, \ldots, C_{n}$, including time and money cost by searching. The values of heuristic information of corresponding searching path are $I_{1}, I_{2}, \ldots, I_{n}$, which mean influence level induced by the success searching.

2) Assume in the searching for the cause of system failure, there are " $n$ " search schemes and " $m$ " event attributes (probability, cost and so on) affect search scheme need to be considered. Search scheme set is denoted by $X=X_{1}, X_{2}, \ldots, X_{n}$, attribute value of search scheme is denoted by $Y=y_{1}, y_{2}, \ldots, y_{m}$. The search decision matrix $A$ is expressed as:

$$
A=\left[\begin{array}{c}
X_{1} \\
X_{2} \\
\ldots \\
X_{n}
\end{array}\right]\left[\begin{array}{cccc}
y_{11} & y_{12} & \ldots & y_{1 m} \\
y_{21} & y_{22} & \ldots & y_{2 m} \\
\ldots & \ldots & \ldots & \ldots \\
y_{n 1} & y_{n 2} & \ldots & y_{n m}
\end{array}\right]
$$

In order to facilitate comparison, the attribute values are unified conversed in $[0,1]$. The normalized matrix $Z_{i j}$ is written as follows.

$$
Z_{i j}=Y_{i j} \div \sqrt{\sum_{i=1}^{n} y_{i j}^{2}}(i=1, \ldots, n ; j=1, \ldots m)
$$

3) In multi-objective decision, in order to ensure all search scheme attributes are taken into account, "least square method" is used to calculate the weighted values of each attribute which reflect the relative materiality of the attribute. Weighted value the larger, import of the attribute greater.

The relative important degree of the attribute " $i$ " to " $j$ " is denoted by $b_{i j}$, and in numerical it's approximately equal to $W_{i} / W_{j}$. The comparison results of "m" attributes are expressed in matrix $\mathrm{B}$.

$$
B=\left[\begin{array}{cccc}
b_{11} & b_{12} & \ldots & b_{1 m} \\
b_{21} & b_{22} & \ldots & b_{2 m} \\
\ldots & \ldots & \ldots & \ldots \\
b_{m 1} & b_{n 2} & \ldots & b_{m m}
\end{array}\right] \approx\left[\begin{array}{cccc}
W_{1} / W_{1} & W_{1} / W_{2} & \ldots & W_{1} / W_{m} \\
W_{2} / W_{1} & W_{2} / W_{2} & \ldots & W_{2} / W_{m} \\
\ldots & \ldots & \ldots & \ldots \\
W_{m} / W_{1} & W_{m} / W_{2} & \ldots & W_{m} / W_{m}
\end{array}\right]
$$

Choose a group of weight values $\left\{W_{1}, W_{2}, \ldots, W_{m}\right\}$, to make sure the quadratic sum of the error $b_{i j} W_{j}-W_{i}$ is the minimum.

$$
Z=\min \left\{\sum_{i=1}^{m} \sum_{j=1}^{n}\left(b_{i j} W_{j}-W_{i}\right)^{2}\right\}
$$

The weight value $\left\{W_{1}, W_{2}, \ldots, W_{m}\right\}$ is constrained by:

$$
\sum_{i=1}^{m} W_{i}=1\left(W_{i}>0\right)
$$

According to equation (2) and equation (5), standardized searching decision matrix $S$ is calculated by the following equation:

$$
S_{i j}=W_{i} Z_{i j}(i=1, \ldots, n ; j=1, \ldots m)
$$

4) The ordering method (TOPSIS) for approaching ideal solution is adopted to determine the best ideal solution and the worst of the negative ideal solution of attribute values, which mean the optimal searching scheme $S^{+}$and the worst scheme $S^{-}$.

$$
\begin{aligned}
S^{+} & =\left\{S_{1}^{+}, S_{2}^{+}, \ldots, S_{n}^{+}\right\} \\
& =\left\{\left(\max _{i} S_{i j} \mid j \in J\right)\left|\left(\min _{i} S_{i j} \mid j \in J^{\prime}\right)\right| \mathrm{i}=1,2, \ldots, \mathrm{n}\right\} \\
S^{-} & =\left\{S_{1}^{-}, S_{2}^{-}, \ldots, S_{n}^{-}\right\} \\
& \left.=\left\{\min _{i} S_{i j} \mid j \in J\right)\left|\left(\max _{i} S_{i j} \mid j \in J^{\prime}\right)\right| \mathrm{i}=1,2, \ldots, \mathrm{n}\right\}
\end{aligned}
$$

In the equation (8), $\boldsymbol{J}$ is the benefit property set and $J^{\prime}$ is the cost property set.

The ideal solution and the negative ideal solution are assumed values and cannot be found in the schemes. The 
solution which is closest to the ideal solution and away from the negative ideal solution is the real solution.

The distances of each solution to the ideal solution are:

$$
D_{i}^{+}=\sqrt{\sum_{j=1}^{m}\left(S_{i j}-S_{i}^{+}\right)^{2}} \quad(\mathrm{i}=1,2, \ldots, \mathrm{n})
$$

The distances of each solution to the negative ideal solution are:

$$
D_{i}^{-}=\sqrt{\sum_{j=1}^{m}\left(S_{i j}-S_{i}^{-}\right)^{2}} \quad(\mathrm{i}=1,2, \ldots, \mathrm{n})
$$

The relative close degree $E_{i}$ is used to measure the distances of the two sizes, and the large value is needed to be search and detect.

$$
E_{i}=D_{i}^{-} /\left(D_{i}^{-}+D_{i}^{+}\right), 0 \leq E_{i} \leq 1
$$

\section{Solving fault diagnosis of fin system using optimal search scheme}

The flow chart of the optimal searching method based on fault tree analysis of the fin stabilizer is shown in Fig3.

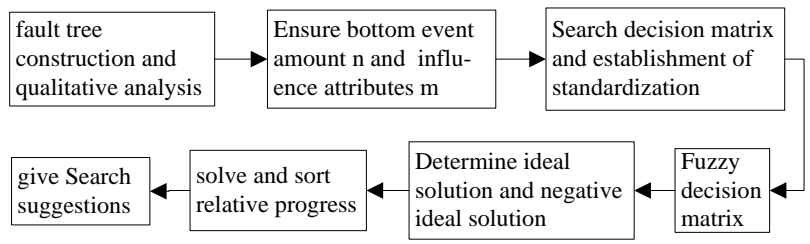

Fig 3 flow chart of the optimal fault searching method of fin

The fault tree of fin stabilizer system is shown in Fig.2, $X_{1}, X_{2}, \ldots, X_{32}$ stands for reasons of the system failure. $I$ for information value search, $C$ for searching cost and $P$ for probability of occurrence, and the rank is shown in Table1. In the table, $I=1$ represents the information value is the largest. $C=1$ represents the search cost is the lowest, and $P=1$ represents the probability of occurrence is the biggest.

The search decision matrix according to this table is:

$$
A=\left[\begin{array}{c}
X_{1} \\
X_{2} \\
\cdots \\
X_{32}
\end{array}\right]\left[\begin{array}{ccc}
25 & 29 & 26 \\
13 & 26 & 25 \\
\cdots & \cdots & \cdots \\
16 & 28 & 23
\end{array}\right]
$$

Matrix $Z$ is got by normative approaching equation (12)

$$
Z=\left[\begin{array}{c}
X_{1} \\
X_{2} \\
\cdots \\
X_{32}
\end{array}\right]\left[\begin{array}{ccc}
0.300 & 0.288 & 0.307 \\
0.156 & 0.258 & 0.295 \\
\ldots & \ldots & \ldots \\
0.192 & 0.278 & 0.271
\end{array}\right]
$$

\begin{tabular}{|c|c|c|c|c|c|c|c|c|c|}
\hline No. & $\begin{array}{l}\text { Fault } \\
\text { cause }\end{array}$ & $\begin{array}{l}\text { Rank } \\
\text { of I }\end{array}$ & $\begin{array}{l}\text { Rank } \\
\text { of C }\end{array}$ & $\begin{array}{l}\text { Rank } \\
\text { of P }\end{array}$ & No. & \begin{tabular}{|l} 
Fault \\
cause
\end{tabular} & $\begin{array}{l}\operatorname{Ran} \\
\mathrm{k} \text { of }\end{array}$ & $\begin{array}{l}\text { Ran } \\
\mathrm{k} \text { of }\end{array}$ & \begin{tabular}{|l|} 
Rank \\
of $P$
\end{tabular} \\
\hline $\mathrm{X} 1$ & $\begin{array}{l}\text { power } \\
\text { switch isn } \\
\text { t open } \\
\end{array}$ & 25 & 29 & 26 & X17 & $\begin{array}{l}\text { DYCJ } \\
\text { fault }\end{array}$ & 17 & 14 & 22 \\
\hline $\mathrm{X} 2$ & $\begin{array}{l}\text { switchboar } \\
\text { d fault }\end{array}$ & 13 & 26 & 25 & X18 & $\begin{array}{|ll|}\text { switch } & \\
\text { fault } & \text { of } \\
\text { master } & \\
\end{array}$ & 26 & 19 & 16 \\
\hline X3 & $\begin{array}{l}\text { Fin } \\
\text { mechanica } \\
1 \\
\text { arrangeme }\end{array}$ & 4 & 1 & 5 & X19 & $\begin{array}{l}\text { spill } \text { fault } \\
\text { of } r \text { master } \\
\text { carton }\end{array}$ & 8 & 20 & 15 \\
\hline $\mathrm{X} 4$ & $\begin{array}{l}\text { ancillary } \\
\text { circuit } \\
\text { fault }\end{array}$ & 19 & 13 & 9 & $\mathrm{X} 20$ & $\begin{array}{l}\text { Set point } \\
\text { of pressure } \\
\text { regulating } \\
\text { spill value } \\
\text { changes or } \\
\text { spill valve } \\
\text { damage } \\
\end{array}$ & 6 & 2 & 2 \\
\hline$x 5$ & $\begin{array}{l}\text { main oil- } \\
\text { way fault } \\
\end{array}$ & 12 & 9 & 6 & $\mathrm{X} 21$ & $\begin{array}{l}\text { air in oil } \\
\text { line }\end{array}$ & 6 & 6 & 4 \\
\hline $\mathrm{x} 6$ & $\begin{array}{l}\text { servo oil- } \\
\text { way } \\
\text { failure }\end{array}$ & 23 & 10 & 7 & $\mathrm{X} 22$ & $\begin{array}{l}\text { pump } \\
\text { discharge } \\
\text { pressure } \\
\text { too small } \\
\end{array}$ & 2 & 5 & 2 \\
\hline $\mathrm{x} 7$ & $\begin{array}{l}\text { hydraulic } \\
\text { pump fault }\end{array}$ & 1 & 7 & 3 & $x 23$ & \begin{tabular}{|l|} 
servo \\
valve fault \\
\end{tabular} & 18 & 3 & 1 \\
\hline X8 & motor fault & 3 & 8 & 11 & X24 & \begin{tabular}{|l|} 
potentiome \\
ter fault
\end{tabular} & 22 & 4 & 3 \\
\hline X9 & $\begin{array}{l}\text { SDCJ } \\
\text { fault }\end{array}$ & 11 & 11 & 10 & $\mathrm{X} 25$ & $\begin{array}{l}\text { relevance } \\
\text { circuit } \\
\text { break }\end{array}$ & 21 & 7 & 4 \\
\hline $\mathrm{X} 10$ & SDJ4 fault & 5 & 12 & 8 & $\times 26$ & line break & 21 & 27 & 21 \\
\hline $\mathrm{X} 11$ & \begin{tabular}{|l|} 
without \\
$380 \mathrm{~V}$ \\
\end{tabular} & 20 & 22 & 12 & $\mathrm{x} 27$ & $\begin{array}{l}\text { reset valve } \\
\text { fault }\end{array}$ & 15 & 24 & 22 \\
\hline X12 & blown fuse & 24 & 21 & 13 & $\mathrm{X} 28$ & \begin{tabular}{|l|} 
locking \\
device
\end{tabular} & 2 & 23 & 18 \\
\hline $\mathrm{X} 13$ & $\begin{array}{l}\text { intermedia } \\
\text { te- } \\
\text { frequency } \\
\text { circuit } \\
\end{array}$ & 5 & 17 & 13 & $\times 29$ & zero drift & 15 & 29 & 24 \\
\hline X14 & \begin{tabular}{|l|} 
amplifier \\
module \\
fault
\end{tabular} & 10 & 18 & 14 & x30 & $\begin{array}{l}\text { micro } \\
\text { switch } \\
\text { drift } \\
\end{array}$ & 7 & 26 & 19 \\
\hline X15 & $\begin{array}{l}\text { gyroscope } \\
\text { fault }\end{array}$ & 9 & 16 & 17 & X31 & \begin{tabular}{|l} 
micro \\
switch \\
break
\end{tabular} & 7 & 25 & 20 \\
\hline
\end{tabular}

Table 1 the main impact factor of the failure reasons of the retractable fin stabilizer

According to the characteristics of the fin stabilizer system and the actual diagnosis data of fault, the judgment matrix B is obtained as equation (14), based on comparison the weight of the information heuristic value, searching costs and the occurrence probability of fault.

$$
B=\left[\begin{array}{ccc}
1 & 1 / 3 & 1 / 2 \\
3 & 1 & 3 \\
2 & 1 / 3 & 1
\end{array}\right]
$$

Due to the method of least square of weighted value, the LaGrange function $L(W, \lambda)$ is built:

$$
L(W, \lambda)=\sum_{i=1}^{3} \sum_{j=1}^{3}\left(W_{i}-C_{i j} W_{j}\right)^{2}+2 \lambda\left(\sum_{i=1}^{3} W_{i}-1\right)
$$


Set $\partial L / \partial W_{l}=0$, then, $K W+\lambda e=0$

Among equation (16),

$$
\begin{aligned}
K=\left[\begin{array}{cccc}
\sum_{i=1}^{m} B_{i 1}^{2}+m-2 & -\left(B_{12}+B_{21}\right) & \ldots & -\left(B_{1 m}+B_{m 1}\right) \\
-\left(B_{21}+B_{12}\right) & \sum_{i=1}^{m} B_{i 2}^{2}+m-2 & \ldots & -\left(B_{2 m}+B_{m 2}\right) \\
\ldots & \ldots & \ldots & \ldots \\
-\left(B_{m 1}+B_{1 m}\right) & -\left(B_{m 2}+B_{2 m}\right) & \ldots & \sum_{i=1}^{m} B_{i m}^{2}+m-2
\end{array}\right] \\
W=\left[W_{1}, W_{2}, \ldots, W_{m}\right]^{T} \\
\quad e=[1,1, \ldots, 1]^{T} \\
m=3
\end{aligned}
$$

Weight vector $W$ is calculated:

$W=[0.3322,0.2733,0.3945]^{T}$

Then standard searching decision matrix $S$ after weighted is written as:

$$
S=\left[\begin{array}{ccc}
0.0997 & 0.0788 & 0.1211 \\
0.0518 & 0.0706 & 0.1165 \\
\ldots & \ldots & \ldots \\
0.0638 & 0.0761 & 0.1072
\end{array}\right]
$$

Ideal solution $S^{+}=\{0.0040,0.0027,0.0093\}$

Negative ideal solution $S^{-}=\{0.1036,0.0788,0.1211\}$

The distance to the ideal solution of each solution

$D_{i}^{+}=\{0.1657,0.1356, \ldots, 0.1361\}$

The distance to the negative ideal solution

$D_{i}^{-}=\{0.0039,0.0526, \ldots, 0.0423\}$

The relative close degree of each solution to the ideal solution

$E_{i}=\{0.0232,0.2796,0.8919,0.5257,0.6986,0.5233,0.9030,0.73$

$34,0.6377,0.7432,0.4052,0.3540,0.6105,0.5262,0.5004,0.438$

$2,0.3266,0.2951,0.5202,0.8856,0.8478,0.9328,0.6724,0.6028$,

$0.5949,0.1833,0.2831,0.5207,0.2432,0.4362,0.4278,0.2370\}$

According to value of $E_{i}$, order of searching scheme is determined. The scheme with the largest $E_{i}$ should be search, detect and diagnose first. According to the above calculation search scheme, the rank of searching scheme is sorting for $X_{22}, X_{7}, X_{3}, X_{20}, X_{21}, X_{10} X_{8}, X_{5}, X_{23}, X_{9}, X_{13}, X_{24}, X_{25}, X_{14}, X_{4}, X_{6}, X_{28}$, the result $X_{19}, X_{15}, X_{16}, X_{30}, X_{31}, X_{11} X_{12}, X_{17}, X_{18}, X_{27}, X_{2}, X_{29}, X_{32}, X_{26}, X_{1}$

is shown in Fig. 4

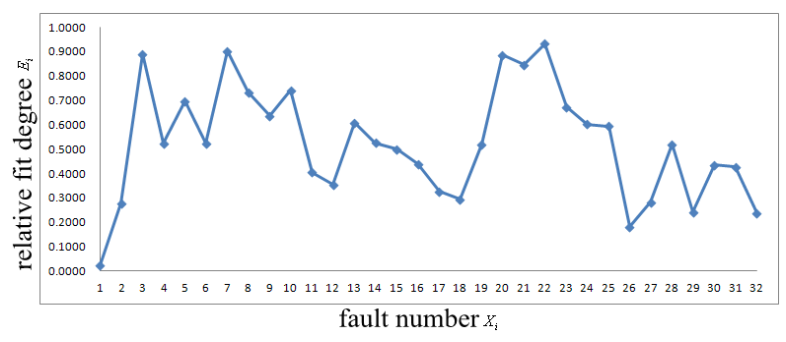

Fig.4 rank orders of searching scheme

If successfully searched, the diagnosis would be stopped. Otherwise, update the established fault decision matrix of fin stabilizer and the searching cost after test, in order to consider the previous results and the present detection result together, and then searching for a new solution until diagnosis is successful.

\section{Conclusion}

In this paper, on the basis of in-depth analysis of antirolling fin system, the fault tree model is established based on fault tree analysis method, and the main failure modes of antirolling fin system are found. Multi-objective optimization decision theory is applied, and multi-IF (impact factors) including fault probability, search costs and illuminating value provided by the searching are comprehensive considered, the most likely path to reach the problem solving is selected in the state space, and the optimal search strategy is determined. As the path of fault reason searching be simplified, the fault of anti-rolling fin system is quickly located, and the efficiency of diagnosis is improved, and it has use for reference for rapid fault location strategy of other complex systems.

\section{References}

[1] Weixin Zhu, "Research on stabilization of large ship," China Shipping, vol. 12, May 2012: 249-251.

[2] Bin $\mathrm{Hu}$, "Intelligent diagnosis system of fin stabilizer faults based on case-based reasoning," Ship Engineering: vol. 33, February 2011: 9092.

[3] Hang Luo, "Research on key issues of fault tree analysis", Ph.D. Dissertation of university of electronic science and technology, 2010.

[4] Gongjing Yu, "Research on testability design and diagnostic strategy optimization technology of equipment," Electronic Measurement Technology: vol. 24, March 2012: 8-11.

[5] Qiang Gai, "Research on failure modes of hydraulic system of ship based on AMET," Chines Journal of Scientific Instrument.vol. 31, August 2010: 63-65.

[6] Huarui Zhang, "Research on the design of optimum searching parameters of phased array radar," Journal of China Ordnance, vol. 33, March 2011: 1062-1065.

[7] Hui Tian, "Application of fault tree analysis in the reliability analysis of oil-gas long pipeline," American Society of Civil Engineers,2013.

[8] Dong Yuhua,"Estimation of failure probability of oil and gas transmission pipelines by fuzzy fault tree analysis,"Journal of Loss Prevention in the Process Industries:vol 18, pp83-88, March 2005.

[9] Marko Čepin, "A dynamic fault tree," Reliability Engineering \& System Safety: vol.75, pp. 83-91, January 2002. 